\title{
APLICABILIDADE DO "REMÉDIO DA REDUÇÃO DE PREÇOS” NA CONVENÇÃO DAS NAÇÕES UNIDAS PARA A VENDA INTERNACIONAL DE MERCADORIAS
}

\author{
APPLICABILITY OF THE "PRICE REDUCTION REMEDY" IN THE UNITED \\ NATIONS CONVENTION FOR INTERNATIONAL MARKET SALE
}

\section{João Paulo Alfredo Carvalho da Costa Lima ${ }^{1}$}

\section{Adriano Fernandes Ferreira ${ }^{2}$}

RESUMO: O respectivo estudo visa analisar a aplicabilidade e historicidade do Remédio da Redução dos Preços em contratos internacionais antes e depois de sua previsão pela Convenção Das Nações Unidas Para A Venda Internacional De Mercadorias, realizar uma pesquisa bibliográfico sobre tal remédio, buscar sua origem, pesquisar apontamentos doutrinários e casos concretos o envolvendo.

PALAVRAS-CHAVE: Remédio da Redução dos Preços, Aplicabilidade, CISG, Mercadorias.

ABSTRACT: The respective study aims to analyze the applicability and historicity of the Price Reduction Remedy in international contracts before and after your prediction by the United Nations Convention on Contracts for the International Sale of Goods. Conduct a bibliographic search on such remedy, search for your origin, search for doctrinal notes and concrete cases involving it.

KEYWORDS: Price Reduction Remedy, Applicability, CISG, Goods.

\footnotetext{
I Acadêmico de Direito na Universidade Federal do Amazonas (UFAM). Email: joaopauloalfredo@gmail.com.

${ }^{2}$ Possui graduação em Direito pelo Centro Universitário de Maringá (2001), mestrado em Direito pela Universidade Gama Filho (2005), é doutor em Ciências Jurídicas pela Universidad Castilha la Mancha, na Espanha (2014) e Pós-Doutor em Direito Pela Universidade de Santiago de Compostela, na Espanha (2019). Atualmente é professor Adjunto IV, da Universidade Federal do Amazonas- UFAM - das disciplinas de Direito Internacional Público e Direito Internacional Privado. Vice-Diretor da Faculdade de Direito da UFAM, Coordenador da Pós-Graduação da Faculdade de Direito e Coordenador do Programa de Mestrado em Direito da Faculdade de Direito da UFAM. Membro da Câmara de Inovação Tecnológica da UFAM. Email: adrianofernandes3@hotmail.com.
} 


\section{INTRODUÇÃO}

$\mathrm{O}$ artigo 50 da $\mathrm{CISG}^{3}$ prevê a reparação da redução do preço quando o vendedor não tiver entregue em conformidade com o contrato. Nessa situação, o comprador tem legitimidade de propor uma redução proporcionalmente ao valor reduzido das mercadorias.

A redução do preço é um remédio a favor do comprador. Oferece ao comprador uma alternativa ao direito de solicitar danos ou evitação (sendo esses remédios à livre escolha do comprador). A redução do preço ainda será possível a ser solicitada mesmo se o prazo do contrato tenha expirado $\left.\left(\operatorname{art} 49,(2) \mathrm{CISG}^{4}\right)\right)$.

O remédio em questão é vedado se o vendedor tiver curado os defeitos das mercadorias nos termos dos artigos $37^{5}$ e $48^{6}$ da CISG, ou se o comprador tiver recusado ao vendedor a oportunidade de tal saneamento.

3 art.5o/CISG: se as mercadorias não estão em conformidade com o contrato e se o preço já foi ou não
pago, o comprador pode reduzir o preço na mesma proporção em que o valor que as mercadorias
realmente entregues tinham no momento da entrega é igual ao valor que bens conformes teriam tido
naquele momento. No entanto, se o vendedor remediar qualquer falha no cumprimento de suas
obrigações de acordo com o artigo 37 ou 48 ou se o comprador se recusar a aceitar o desempenho pelo
vendedor de acordo com esses artigos, o comprador não poderá reduzir o preço. ${ }^{4}$ art.49/CISG: (2) Todavia, se o vendedor tiver entregue as mercadorias, o comprador perderá o direito de declarar o contrato rescindido.

${ }_{5}$ Art.38/CISG: em caso de entrega das mercadorias antes da data prevista para a entrega, o vendedor poderá, até tal data, entregar a parte faltante ou completar a quantidade das mercadorias entregues, ou entregar outras mercadorias em substituição àquelas desconformes ao contrato ou, ainda, sanar qualquer desconformidade das mercadorias entregues, desde que não ocasione ao comprador inconvenientes nem despesas excessivas. Contudo, o comprador mantém o direito de exigir indenização por perdas e danos, de conformidade com a presente Convenção.

${ }^{6}$ Art.48/CISG: (I) Sem prejuízo do disposto no artigo 49, o vendedor poderá, mesmo após a data da entrega, sanar por conta própria qualquer descumprimento de suas obrigações, desde que isto não implique demora não razoável nem cause ao comprador inconveniente ou incerteza não razoáveis quanto ao reembolso, pelo vendedor, das despesas feitas pelo comprador. Contudo, o comprador manterá o direito de exigir indenização das perdas e danos, nos termos da presente Convenção.

(2) Se o vendedor pedir ao comprador que lhe faça saber se aceita o cumprimento, e o comprador não lhe responder em prazo razoável, o vendedor poderá executar suas obrigações no prazo indicado em seu pedido. O comprador não poderá, antes do vencimento desse prazo, exercer qualquer direito ou ação incompatível com o cumprimento, pelo vendedor, das obrigações que a ele incumbem.

(3) Quando o vendedor comunicar ao comprador a intenção de cumprir suas obrigações em prazo determinado, será considerado incluído o pedido, nos termos do parágrafo anterior, para que o comprador lhe faça saber sua decisão.

(4) O pedido ou a comunicação feita pelo vendedor, nos termos dos parágrafos (I) e (2) do presente artigo, não terá efeito se não for recebido pelo comprador. 
Todos os créditos à doutoranda Naína Tumelero, que publicou com grande maestria o artigo “Tipos de pesquisa: da abordagem, natureza, objetivos e procedimentos; (2019)", segue a pesquisas que foram adotadas no respectivo estudo:

Quanto à abordagem da pesquisa científica, foi adotada a pesquisa qualitativa, essa modalidade é descritiva, o pesquisador usará sua indução para análise de dados, ou seja, o autor usou dados para dar uma solução subjetiva ao caso.

Quanto à natureza, foi utilizada a pesquisa aplicada, que visa gerar conhecimentos para aplicação prática no respectivo caso ou outro acontecimento futuro.

Quanto ao objetivo da pesquisa, foi adotada a pesquisa exploratória, foram levantados dados por meio de pesquisas bibliografias, jurisprudência e doutrina acerca da matéria, com o objetivo de explorar por completo o objeto da pesquisa para a melhor conclusão.

Quanto aos procedimentos da pesquisa, foi adotada a pesquisa bibliográfica por meio de artigos, livros e periódicos publicados; pesquisa ex-post-facto que investiga a causa e feito após a ocorrência do fato; estudo de caso que envolve um estudo mais aprofundado de um caso concreto, para o máximo entendimento do caso.

\section{REMÉDIO DA REDUÇÃO DE PREÇOS}

O remédio da redução de preço é tradicionalmente oriundo do civil law que deriva da actio quanti minoris ${ }^{7}$ do direito romano. Essa lei romana permitia a um comprador sustentar uma ação contra o vendedor para reduzir o preço decorrente da defeituosidade do bem.

Essa ação originou-se de um Edito dos Aediles ${ }^{8}$ que almejava a "reprimir as práticas de vendedores de escravos e gado nos mercados da cidade". Se um comprador

\footnotetext{
7 Ação de diminuição de preço.

${ }^{8}$ Eram os assistentes dos tribunos em assuntos como os tribunos a eles confiados, entre os quais se enumerava a audição de causas de menor importância.
} 
teve a consciência e conhecimento de certos defeitos explícitos que o fornecedor omitiu, o comprador poderia trazer uma redução de preço ou a própria recessão contratual.

As origens do direito romano refletiram em disposições contemporâneas em países que adotam o civil law. No Código Civil Francês (art.I644) permite que um comprador recupere parte do valor da compra, o montante a ser determinado por especialistas, ou rescindir o contrato e recuperar o preço total. Na Alemanha, o §459 da BGB9 (Bürgerliches Gesetzbuch) estabelece: se os bens não tiverem as qualidades prometidas ou contiverem defeitos que diminuam o uso normal dos bens ou o uso previsto no contrato, o comprador tem opção de rescindir o contrato, ou de reduzir o preço de acordo com a fórmula estabelecida no $\$ 472$ da BGB.

No Civil Law, a rescisão como a redução do preço são remédios comuns para o comprador que não teve o contrato adimplido por completo, e o dano é a exceção. Em caso de falha contratual, o recurso de redução de preço fornece por meio de compensação monetária, mesmo que não haja danos, a conformidade contratual.

É de suma importância destacar a redução de preço quando o contrato for parcialmente cumprido, ou foi entregue uma quantidade insuficiente de bens. Esse recurso terá o mesmo efeito, proporcionalmente ao valor do inadimplemento (razoabilidade, princípio da CISG), o comprador poderá confiar no contrato de exclusio non adimpleti para reter aquela parte do preço de compra relacionada à inadimplência.

No ordenamento jurídico brasileiro, tal recurso está previsto no artigo 422 do Código Civil de $2002^{10}$, que faculta ao adquirente requerer o "abatimento" do preço ou a extinção contratual, com as respectivas perdas e danos. Todavia, só permite a redução do preço em caso de vícios ocultos, contudo, o artigo anterior não entra em conflito, pois a CISG somente se aplica em contratos internacionais de compra e venda de bens.

\footnotetext{
9 Bürgerliches Gesetzbuch: Código Civil Alemão.

1o Art. 442 do CC/2002 (art. I.Ios do CC/1916): "Em vez de rejeitar a coisa, redibindo o contrato [art. 44I - anterior I.IOI], pode o adquirente reclamar abatimento no preço".
} 
Nas relações consumeristas, aplica-se o artigo 20 do Código do Consumidor ${ }^{\mathrm{II}}$, dispositivo similar aos debatidos nesse tópico. Conclui-se a direta "herança" do direito romano nas relações de conflitos contratuais no Direito brasileiro, e a aplicabilidade do remédio da redução do preço para a solução dos mesmos.

\section{PRÉ-REQUISITOS PARA REDUÇÃO DE PREÇO}

A aplicação do dispositivo so da CISG é necessária, quando as mercadorias não estiverem em conformidade com o contrato, como dito antes. Logo, a não conformidade (prevista e delimitada pelo o art.35 da CISG ${ }^{12}$ ) é o primeiro requisito; pode ser por defeito de qualidade, quantidade, descrição, embalagem ou até a falta de documentação relativa às mercadorias.

Todavia, esse remédio não pode ser utilizado quando houver atraso do produto desejado ou violação de qualquer obrigação do vendedor, salvo se não seja entregar as mercadorias em conformidade.

Logo, a redução será aplicada se a não conformidade constituir uma violação simples ou fundamental do contrato, observadas as excludentes de responsabilidade

\footnotetext{
${ }^{11}$ Art. 20/CISG: O fornecedor de serviços responde pelos vícios de qualidade que os tornem impróprios ao consumo ou lhes diminuam o valor, assim como por aqueles decorrentes da disparidade com as indicações constantes $\mathrm{da}$ oferta ou mensagem publicitária, podendo o consumidor exigir, alternativamente e à sua escolha: III - o abatimento proporcional do preço.

I2 Artigo 35/CISG: (I) O vendedor deverá entregar mercadorias na quantidade, qualidade e tipo previstos no contrato, acondicionadas ou embaladas na forma nele estabelecida.

(2) Salvo se as partes houverem acordado de outro modo, as mercadorias não serão consideradas conformes ao contrato salvo se:

(a) forem adequadas ao uso para o qual mercadorias do mesmo tipo normalmente se destinam;

(b) forem adequadas a algum uso especial que, expressa ou implicitamente, tenha sido informado ao vendedor no momento da conclusão do contrato, salvo se das circunstâncias resultar que o comprador não confiou na competência e julgamento do vendedor, ou que não era razoável fazê-lo;

(c) possuírem as qualidades das amostras ou modelos de mercadorias que o vendedor tiver apresentado ao comprador;

(d) estiverem embaladas ou acondicionadas na forma habitual para tais mercadorias ou, à falta desta, de modo apropriado à sua conservação e proteção.

(3) O vendedor não será responsável por qualquer desconformidade das mercadorias em virtude do disposto nas alíneas (a) a (d) do parágrafo anterior, se, no momento da conclusão do contrato, o comprador sabia ou não podia ignorar tal desconformidade.
} 
previstas no art.79 da CISG ${ }^{13}$. Entretanto, existirá a possibilidade de aplicar esse remédio, mesmo se parte dos danos forem excluídos por esse artigo.

É necessário que o comprador notifique previamente a falta de conformidade dos bens, se não fizer, o comprador não estará vinculado ao cumprimento do contrato ou poderá perder todo o seu investimento (art.39 da CISG) ${ }^{14}$. O artigo 44 da CISG ${ }^{15}$ destaca a possiblidade do comprador justificadamente se desculpar pela falha em notificar tais desconformidades, mantendo a possibilidade da redução do preço ou ao menos de reclamar pelos danos que não sejam por lucros cessantes. Além disso, o comprador deve expressar a intenção de reduzir o preço, o simples ato de não pagar os bens é suficiente para reivindicar a redução do preço.

O comprador prejudicado poderá adotar outros remédios, poderá combiná-los ao remédio da redução de preço, exemplo: o comprador poderá combinar a redução com uma reivindicação de danos. Tal possibilidade está prevista no artigo 45 da

\footnotetext{
${ }^{13}$ Artigo 79/CISG: (I) Nenhuma das partes será responsável pelo inadimplemento de qualquer de suas obrigações se provar que tal inadimplemento foi devido a motivo alheio à sua vontade, que não era razoável esperar fosse levado em consideração no momento da conclusão do contrato, ou que fosse evitado ou superado, ou ainda, que fossem evitadas ou superadas suas consequências.

(2) Se o inadimplemento de uma das partes for devido à falta de cumprimento de terceiro por ela incumbido da execução total ou parcial do contrato, esta parte somente ficará exonerada de sua responsabilidade se: (a) estiver exonerada do disposto no parágrafo anterior; e (b) o terceiro incumbido da execução também estivesse exonerado, caso lhe fossem aplicadas as disposições daquele parágrafo.

(3) A exclusão prevista neste artigo produzirá efeito enquanto durar o impedimento.

(4) A parte que não tiver cumprido suas obrigações deve comunicar à outra parte o impedimento, bem como seus efeitos sobre sua capacidade de cumpri-las. Se a outra parte não receber a comunicação dentro de prazo razoável após o momento em que a parte que deixou de cumprir suas obrigações tiver ou devesse ter tomado conhecimento do impedimento, esta será responsável pelas perdas e danos decorrentes da falta de comunicação.

(5) As disposições deste artigo não impedem as partes de exercer qualquer outro direito além da indenização por perdas e danos nos termos desta Convenção.

${ }^{14}$ Artigo 39/CISG: (I) O comprador perderá o direito de alegar a desconformidade se não a comunicar ao vendedor, precisando sua natureza, em prazo razoável a partir do momento em que a constatar, ou em que deveria tê-la constatado. (2) Em qualquer caso, o comprador perderá o direito de alegar a desconformidade se não a comunicar ao vendedor no prazo máximo de dois anos a partir da data em que as mercadorias efetivamente passarem à sua posse, salvo se tal prazo for incompatível com a duração da garantia contratual.

is Artigo 44/CISG: Sem prejuízo do disposto no parágrafo (I) do artigo 39 e no parágrafo (I) do artigo 43, o comprador poderá reduzir o preço, conforme o artigo so, ou exigir a indenização das perdas e danos, excluídos os lucros cessantes, se puder apresentar justificativa razoável por não ter efetuado a necessária comunicação.
} 
CISG $^{\mathrm{I}}$. Porém, os danos só podem ser concedidos para perdas diferentes do valor reduzido dos bens, pois essa perda já reflete na redução do preço.

\section{${ }_{3}$ CÁlCULO DA REDUÇÃo DE PREÇOS}

A redução do valor de preço deve ser comprimida proporcionalmente ao inadimplido e o custo será determinado a partir da entrega real no local de entrega, ou seja, será calculado pelo valor dos bens entregues (ou não) não conformes com o pedido, e o seu valor será o do momento da entrega.

É de livre acordo as partes estipularem uma maneira específica de cálculo, exemplo no caso "Citações de casos alemães não identificam partes no processo" ${ }^{17}$, cuja decisão ratificou que as partes concordaram na redução do preço original, em decorrência que o comprador não iria revender mercadorias não conformes ao melhor valor possível.

Em casos em que os bens entregues não detêm valor algum, o valor será nulo. O comprador mantém essa possibilidade mesmo, por decurso do prazo do contrato. Logo, o remédio da redução de preços terá os mesmos efeitos do remédio impeditivo, lembrando que não há vinculação do comprador devolver a mercadoria.

Quando as partes não tiverem um acordo entre si, um perito poderá ser contratado para liquidar os danos.

\section{LOCAL DE ATUAÇÃO}

A execução do remédio deverá ser onde as mercadorias foram entregues, pois o comprador já pagou (ou não como previsto neste artigo) o preço do bem, logo o art.5o da CISG será sua base para sua reivindicação.

\footnotetext{
${ }^{16}$ Artigo 45 (I) Se o vendedor não cumprir qualquer das obrigações que lhe couberem de acordo com o contrato ou com a presente Convenção, o comprador poderá: (a) exercer os direitos previstos nos artigos 46 a 52; (b) exigir a indenização das perdas e danos prevista nos artigos 74 a 77. (2) O comprador não perde o direito à indenização das perdas e danos por exercer seu direito a outras ações. (3) Não poderá o juiz ou tribunal arbitral conceder ao vendedor qualquer período de graça, quando o comprador exercer ação contra a violação de contrato.

${ }_{17}$ Caso CLOUT No. 825 [ALEMANHA Oberlandesgericht Köln I4 de agosto de 2006].
} 
Todavia a CISG não cobre o caso em que o comprador já pagou o preço, entretanto terá direito de solicitar uma redução do preço e um respectivo reembolso. $\mathrm{E}$ foi entendido pela decisão (na suprema corte da Suíça ${ }^{18}$, que o comprador poderá recuperar tal monetização se a lei nacional sobre enriquecimento sem causa não a contrariar.

Além do fato, é indicado casualmente que o comprador tem o ônus de provar a redução do preço.

\section{CONCLUSÃO}

$\mathrm{O}$ artigo 50 da CISG tem uma importância no cotidiano internacional e o remédio previsto (da redução de preços) tem aplicabilidade em diversos países da civil law, e possui uma carga histórica originária do direito romano. É necessário destacar tal relevância por ser tão rotineiro e útil para solucionar litígios contratuais.

O dispositivo confere o direito de reduzir o preço de bens não conformes em vez de reivindicar indenização, consequentemente a rescisão do contrato; ou contribui a determinar quanto o comprador deve ao vendedor por bens não conformes, advindas de circunstâncias fortuitas, liberando o vendedor da responsabilidade dos danos.

\section{REFERÊNCIAS}

BERNINI, Giorgio. As Leis Uniformes sobre Vendas Internacionais, Convenções de Haia de 1964, 3 J. World Trade L. p. 689 (1969).

Convenção das nações unidas sobre contratos de compra e venda internacional de mercadorias- III Anuário Brasileiro De Direito Internacional; Volume I; tradução de Eduardo Grebler e Gisely Radael.

DE ZULUETA, Francis, “A Lei Romana da Venda”, página 50 (1957).

${ }^{18}$ Caso CLOUT No. 894 [SWITZERLAND Bundesgericht 7 de julho de 2004] 
História legislativa do artigo so da CISG: Escola de Direito Pace Instituto de Direito Comercial Internacional - última atualização em I2 de julho I999.

HONORÉ, A.M. The history of the Aedilitian actions from Roman to RomanDutch law em Daube. Studies in the Roman Law of Sale. 132-159 (1959).

LIU, Chengwei. Redução de Preços por Não Conformidade: Perspectivas da CISG, Princípios UNIDROIT, PECL e Jurisprudência [2 $2^{-}$edição: atualização anotada do caso (março de 2005)].

NEWARK, F.H. Reviewed Work: Studies in the Roman Law of Sale. Dedicated to the Memory of Francis de Zulueta by David Daube. The Cambridge Law Journal. Vol. I8, No. I (Abr., 1960), pp. II2-II4 (3 páginas); Publicado por: Cambridge University Press.

SCHUTZ, Hebert Mendes de Araújo. Da necessidade de adesão do Brasil à convenção da ONU sobre contratos de compra e venda internacional de mercadorias. Revista Jus Navigandi, ISSN 1518-4862, Teresina, ano 16, n. 2974, 23 ago. 2011. Disponível em: 〈https://jus.com.br/artigos/19834〉. Acesso em: I jun. 2019.

SONDAHL, Erika. Entendendo o remédio da redução de preços: Um meio para promover uma aplicação mais uniforme da Convenção das Nações Unidas sobre contratos para a venda internacional de mercadorias" - abril de 2003.

SHIN, Chang-Sop. Declaration of price reduction under the cisg article so price reduction remedy.

UNCITRAL, Resumo da jurisprudência da Convenção das Nações Unidas sobre a Venda Internacional de Mercadorias, 2012.

3.00o casos Io.00o anotações de casos UNCITRAL- Escola de Direito Pace Instituto de Direito Comercial Internacional - Última atualização em 22 de outubro de 2015. 
TUMELERO, Naína. Tipos de pesquisa: da abordagem, natureza, objetivos e procedimentos. Mettzer, 20/09/2019. Disponível em < https://blog.mettzer.com/tipos-de-pesquisa/\#Pesquisa-exploratoria>. Acessado em $27 / \mathrm{II} / 2020$. 